Abant Tıp Dergisi

Abant Medical Journal

Özgün Makale / Cilt 8 Sayı 1 Yıl 2019

Original Article / Volume 8 Issue 1 Year 2019

Çocuk Acil Servisinde Televizyon Düşmesi İle İlişkili Yaralanmalar: Kafa ve Yüz Yaralanmalarının Yüksek Oranı

\title{
Television Tip Over Related Injuries in Pediatric Emergency Department: High Rate of Head and Face Trauma
}

Sinan Oğuz, Deniz Tekin, Funda Kurt, Veli Korkmaz, Emine Suskan

Ankara Üniversitesi Tıp Fakültesi, Çocuk Sağıı̆ı ve Hastalıkları, Çocuk Acil Bilim Dalı, Ankara, Türkiye

\section{Özet}

GíRiş ve AMAÇ: Son yıllarda çocuklarda televizyon düşmesi ilişkili yaralamalarda önemli bir artış olmuştur. Ülkemizden konu ile ilgili sınırlı sayıda çalışma vardır. Bu çalışmada üzerine televizyon düşmesi sonrası Çocuk Acil Servisine başvuran olguların klinik özellikleri sunularak, baş ve yüz yaralanmalarının sıklı̆̆ına dikkat çekmek amaçlanmıştır.

YÖNTEM ve GEREÇLER: Haziran 2012- Aralık 2014 tarihleri arasında, Çocuk Acil Servisine üzerine televizyon düşmesi sonrası başvuran olgular bilgi işletim sistemi kullanılarak geriye dönük değerlendirilmiştir. Olguların demografik özellikleri, yaralanma bölgesi, bilgisayarlı tomografi görüntüleme sonuçları, tedavi şekilleri, izlem yerleri ve prognozları incelenmiştir.

BULGULAR: Çalışmaya dâhil edilen 22 olgunun yaş ortalamaları 4,16 yıl (11ay-12yıl) olarak bulunmuştur. On yedi $(\% 77,3)$ olgunun beş yaş ve altında olduğu görülmüştür. Kız ve erkekler eşit oranda bulunmuştur. Yirmi bir olgunun izlem ve tedavisi çocuk acil gözlem odasında tamamlanmışır. Hiçbir olguya cerrahi girişim yapılmamış, ölen olgu olmamıştır. On yedi $(\% 77,3)$ olguda baş, boyun ve yüz bölgesinde yaralanmaya ait bulgular saptanmıştır.

TARTIŞMA ve SONUÇ: Televizyon düşmesi ile ilişkili yaralanmalarda baş ve boyun bölgelerinin daha sık etkilendiği görülmüştür. Aileler bu yaralanmalar konusunda bilgilendirilmeli ve ev kazalarını önleme programları düzenlenmelidir. Çocuklar iyi monte edilmemiş televizyonlardan uzak tutulmalıdır.

Anahtar Kelimeler: Çocuk, Çocuk Acil, Televizyon Düşmesi, Travma, Kafa Travması

\section{Abstract}

INTRODUCTION: Television tip over related injuries in children have increased in recent years. There are limited numbers of studies on the subject from our country. In this study we presented clinical characteristics of patients who admitted to the our Pediatric Emergency Department after television tip over related injuries and we want to emphasize the high incidence of head and face injuries in this type of trauma.

METHODS: This retrospective study performed on patients admitted to Pediatric Emergency Department from June 2012 to December 2014, with television tip over related injuries. Demographic features, injury region, computed tomography results, treatment options, follow up locations and prognoses of cases have been evaluated.

RESULTS: Twenty two patients were included in the study and mean age was 4.16 years (11 months- 12 years). Seventeen $(77.3 \%)$ cases were under five years. Boys and girls were equal. Twenty-one of patients' follow-up and treatment have been completed in the emergency observation room. No patient underwent to surgery and no patient died. Head, neck and facial injuries were detected in seventeen (77.3\%) cases. DISCUSSION AND CONCLUSION: Head and neck areas were most commonly affected region of body parts with television tip over related trauma. Families should be informed about these injuries and home accidents prevention programs should be organized. Children should be kept away from television not well assembled.

Keywords: Children, Pediatric Emergency, Television tip over, Trauma Head Trauma

yıllarda televizyon düşmesine bağlı yaralanma olgularında artma olmuştur (2). ABD verilerine göre 2000-2011 yılları arasında 215 çocuk televizyona bağlı olaşan yaralanmalar nedeniyle hayatını kaybetmiştir (3). Ancak televizyon düşmesine bağlı yaralanmalarla ilgili ülkemizden az sayıda çalışma mevcuttur $(4,5)$.

Bu çalışmada üzerine televizyon düşmesi sonrası çocuk acil bilim dalımıza başvuran olgular sunularak, baş ve yüz yaralanmalarının sıklığına

İyi monte edilmemiş televizyonlar tek başına keşfe çıkan küçük çocuklar için önemli yaralanmalara neden olabilmektedir. Son 
dikkat çekmek amaçlanmıştır.

\section{GEREÇ ve YÖNTEM}

(Dergi yazım kurallarına uymak için çalışmanın yapıldığı hastane adı yazılmamıştır) Üniversitesi Çocuk Acil Bilim Dalına yılda ortalama 75 bin çocuk olgu başvurmaktadır. Merkezde ve ulaşımı kolay bir konumda yerleşik olması nedeni ile tüm Ankara'dan, farklı sosyo-ekonomik düzeyde, olgu başvurusu olmaktadır. Ayrıca Ankara dışından da ayaktan veya ambulans ile çocuk acil servisimize hasta kabul edilmektedir.

Bu çalışmada 01.06.2012- 31.12.2014 tarihleri arasında, (dergi yazım kurallarına uymak için çalışmanın yapıldığı hastane adı yazılmamıştır) Üniversitesi Çocuk Acil Bilim Dalına, üzerine televizyon düşmesi sonrası başvuran 22 olgu geriye dönük değerlendirilmiştir. Olguların demografik özellikleri, yaralanma bölgesi, bilgisayarlı tomografi görüntüleme sonuçları, tedavi şekilleri ve izlem yerleri incelenmiştir. Olgular bilgi işletim sitemi ve çocuk acil kayıtları taranarak bulunmuştur.

\section{İstatistiksel Analiz}

İstatistiksel verilerin hesaplanmasında SPSS ver. 18.0 for Windows (SPSS Inc.; Chicago, IL, ABD) programı kullanılmıştır. Tanımlayıcı istatistik yapılmıs olup, nitelik belirten veriler sayı ve yüzde olarak sunulmuştur.

\section{BULGULAR}

Olguların yaş ortalamaları 4,16 yıl (11ay-12yıl) olarak bulunmuştur. On yedi $(\% 77,3)$ olgunun beş yaş ve altında olduğu görülmüştür. Kız erkek oranı 1 olarak bulunmuştur. Dört olgunun fizik incelemesinde yaralanmaya ait bulgu saptanmamıştır. On yedi $(\% 77,3)$ olguda baş, boyun ve yüz bölgesinde yaralanmaya ait bulgular saptanmıştır. Sekiz olguda alın, beş olguda burun ve üç olguda göz çevresinde yaralanma bulgusu kaydedilmiştir. iki olguda subgaleal hematom, iki olguda kafatası kırığı saptanmıştır. Kafatası kırı̆ı̆ ve subdural hematom saptanan dört yaşında kız olgu Beyin Cerrahisi servisinde yatırılmıştır. Diğer tüm olgular acil gözlem odası izlemi sonrası taburcu edilmiştir. Hiçbir olguya cerrahi girişim yapılmamış, ölen olgu olmamıştır. Ek yaralanmaları tespiti için üç olguya abdominal ultrasonografi, dokuz olguya tam kan sayımı ve biyokimya ve beş olguya idrar tahlili yapıldığı tüm sonuçların normal sınırlarda saptandığı görülmüştür. Taburculuk öncesi ailelere ev kazaları hakkında uyarılarda bulunulmuştur.

\section{TARTIŞMA}

Televizyon düşmesine bağlı yaralanma sıklığının son yıllarda artış göstermektedir. Televizyonların şekil ve boyutlarındaki değişiklikler onları daha dengesiz hale getirmiştir $(2,3)$. Ev kazaları sonucu çocuklar çeşitli cisimlerin altında kalabilir. Televizyon bu cisimler içinde en önde yer almaktadır (6). Özellikle beş yaş altındaki çocuklar risk altındadır. 1-3 yaş arası en riskli dönem olarak karşımıza çıkmaktadır (3). Çalışmamızda bizde literatur ile uyumlu sonuçlara ulaştık. Erkek cinsiyet başka bir risk faktörü olarak belirtilmektedir(4, 7-9). Çalışmamızda kız ve erkeklerin eşit olması, çevresel özelliklere ve olgu sayısındaki azlığa bağlı olabilir.

Televizyon düşmesine bağlı en önemli yaralanmalar santral sinir sitemini etkilemekte, bu durum mortalite ve morbiditeyi arttırmaktadır $(2,7,8,10)$. Olgularımızda $\% 77,3$ oranda kafa yaralanmasına ait bulgular saptanmıştır. İsrail'de yapılmış bir çalışmada çalışmamıza benzer oranlarda baş boyun yaranması görüldüğü belirtilmiştir (9). Baş ve boynun yüzeysel yaralanmaları sık görülmektedir. Çalışmamızda en sık yaralanma yerinin yüz bölgesi olduğunu gördük. Bu durum, bu tür olgularda yüz yaralanması açısından dikkatli olunmasının uygun olduğu düşünülmüştür. Televizyon düşmesi sonrası oluşan yaralanmalarda kafa yaralanmasının sık olması çocuklarda kafanın görece daha büyük olması ile açıklanabilir. Ayrıca çalışmamızda alın ve burun gibi bölgelerin daha sık etkilenmiş olması baştaki çıkıntılı bölgelerin televizyon tarafından direk etkilenmesi ile ilişkili olabilir.

Televizyon düşmesi sonrası ölümlerin en önemli sebebi kafa yaralanması sonucu oluşan kafa içi kanamalardır. Ülkemizde yapılmış çalışmalarda ölüm oranı \%5,6-11,9 arasında bildirilmiştir (4, 5). Çalışmamızda iki olguda kafatası kırığı saptanmış olmasına karşın cerrahi girişim yapılmamış ve ölen olgu olmamıştır. Bu durum 
acil servisimize çalışma döneminde televizyon düşmesi sonrası ağır yaralanma olgusunun başvurmaması ile ilişkili olabilir.

Televizyon düşmesine bağlı yaralanan bir diğer önemli vücut bölgesi de ekstremitelerdir. Sıklıkla üst ekstremitede yumuşak doku hasarı saptanmasına karşın kemik kırıkları da görülebilmektedir(5, 11, 12). Çalışmamızda ekstremite yaralanmaları \%9 oranında görülmüş olup iki olguda da yaralanma yumuşak dokuya sınırlı idi.

Televizyon boyutlarının artması görece küçük çocukların genel vücut yaralanmasına maruz kalmasına neden olmaktadır. Ülkemizden on yıllık verilerin geriye dönük olarak değerlendirildiği bir çalışmada, olguların beşte birinin genel vücut yaralanmasına maruz kaldığı gösterilmiştir(4). Bu çocuklarda göğüs ve karın yaralanmaları da görülebilir(5). Bu nedenle televizyon altında kalarak yaralanmaya maruz kalmış olguların genel vücut yaralanması gibi değerlendirilmesi, öykü ve fizik incelemelere göre tedavi planının yapılması gerekmektedir. Bizim serimizde dokuz olguda ek yaralanmaların tespiti için yapılan tetkikler normal sınırlarda bulunmuştur.

Televizyon düşmesi sonrası yaralanma için en önemli risk faktörü evde çocukların iyi monte edilmemiş televizyonlarla yalnız bırakılmasıdır. Önemli oranda olguda yaralanma görgü şahidi olmaz(8). Görgü şahitsiz yaralanmalar olgu değerlendirmesini zorlaştırmaktadır. Yaralanmalar sıklıkla çocukların televizyon ünitelerine çarpmaları veya tırmanmaları sonucu olmaktadır(2). Çalışmamızın geriye dönük yapılmış olması nedeni ile tüm olgularda yaralanma mekanizması ile ilgili bilgilere ulaşamadık.

Türk Halkının \% 54,6'sının en az bir televizyona sahip olduğu saptanmıştır(1). Televizyon satışlarındaki artış ile televizyon düşmesine bağlı yaralanmalar arasında pozitif ilgileşim saptanmıştır(9, 13). Ülkemizde de son yıllarda yaşanan teknoloji çılgınlığına bağlı olarak bu tür yaralanmaların artacağı öngörülebilir. Alınacak basit tedbirlerle önemli mortalite ve morbidite sebebi olan bu tür yaralanmaların önüne geçilebilecektir.
Çalışmamızın tek merkezden ve geriye dönük olarak yapılması en önemli kısıtılığı olmuştur. Tüm olgularda yaralanma mekanizması ve televizyon boyutları ile ilgili net bilgilere ulaşılamamıştır. Olgulara yapılacak tetkiklere ve uygulanacak tedaviye olguyu değerlendiren ekip karar vermiştir. Ayrıca veriler bilgi işletim siteminden geriye dönük alındığından sonuçları etkileyebilecek bazı olguları kaçırmış olabiliriz. Çok merkezli ve ileriye dönük çalışmalar ile daha objektif sonuçlara ulaşılacağı açıktır.

\section{SONUÇ}

Sonuç olarak televizyon düşmesi ile ilişkili yaralanmalar her geçen gün artmaktadır. Olguların özellikle kafa ve yüz yaralanmaları açısından değerlendirilmesi önemlidir. Potansiyel olarak ölümcül bu yaralanmalar konusunda aileler bilgilendirilmeli ve ev kazalarını önleme programları düzenlenmelidir. Çocuklar iyi monte edilmemiş televizyonlardan uzak tutulmalıdır.

\section{REFERENCES}

1. RadyoveTelevizyonÜstKurulu. Televizyon İzleme Eğilimleri Araştırması-2. 2009.

2. Cusimano MD, Parker N. Toppled television sets and head injuries in the pediatric population: a framework for prevention. Journal of neurosurgery Pediatrics. 2016;17(1):3-12.

3. De Roo AC, Chounthirath T, Smith GA. Television-related injuries to children in the United States, 1990-2011. Pediatrics. 2013;132(2):267-74.

4. Guloglu R, Sarici IS, Bademler S, Emirikci S, Issever H, Yanar $\mathrm{H}$, Ertekin C. Falling television related child injuries in Turkey: 10-year experience. Turkish journal of trauma \& emergency surgery. 2012;18(1):61-4.

5. Gokhan S, Kose O, Ozhasenekler A, Orak M, Ustundag M, Guloglu C. Mortality and morbidity in children caused by falling televisions: a retrospective analysis of 71 cases. International journal of emergency medicine. 2010;3(4):305-8.

6. Turan Y, Uysal C, Korkmaz M, Yılmaz T, Göçmez C, Özevren $H$, Gören S, Ceviz A. Kaza ile üzerine cisim düşmesine bağı hastaneye başvuran hastaların değerlendirilmesi. Dicle Tıp Dergisi. 2015;42(1):51-4.

7. Befeler AR, Daniels DJ, Helms SA, Klimo P, Jr., Boop F. Head injuries following television-related accidents in the pediatric population. Journal of neurosurgery Pediatrics. 2014:1-4.

8. Rutkoski JD, Sippey M, Gaines BA. Traumatic television tipovers in the pediatric patient population. The Journal of surgical research. 2011;166(2):199-204.

9. Sikron F, Glasser S, Peleg K. Children injured following TV tipovers in Israel, 1997-2003. Child: care, health and development. 2007;33(1):45-51.

10. Gottesman BL, McKenzie LB, Conner KA, Smith GA. Injuries 
From furniture tip-overs among children and adolescents in the United States, 1990-2007. Clinical pediatrics. 2009;48(8):851-8.

11. Ota FS, Maxson RT, Okada PJ. Childhood injuries caused by falling televisions. Academic emergency medicine. 2006;13(6):700-3.

12. DiScala C, Barthel M, Sege R. Outcomes from television sets toppling onto toddlers. Archives of pediatrics \& adolescent medicine. 2001;155(2):145-8.

13. Murray KJ, Griffin R, Rue LW, 3rd, McGwin G, Jr. Recent trends in television tip over-related injuries among children aged 0-9 years. Injury prevention. 2009;15(4):240-3. 